\section{Rocío Oviedo Pérez de Tudela}

Doctora en Literatura Hispánica y en Periodismo. Catedrática de Literatura Hispanoamericana en la Universidad Complutense de Madrid. Entre sus investigaciones ha ocupado un lugar preferente la lírica, tanto en la vanguardia (César Vallejo, Pablo Neruda), como en la poesía contemporánea de Perú y México, y en especial Octavio Paz. El modernismo ha sido un lugar constante en su producción crítica, como demuestran las ediciones de poesía modernista (Silva, Poesías, Castalia, 1997; Rubén Darío, Cantos de vida y Esperanza, Ollero y Ramos, 2004; Herrera y Reissig, Poesías, en prensa). En los últimos años el modernismo ha alternado su importancia con la dedicación a los cronistas de Indias, como reflejan las biografías redactadas para la Real Academia de la Historia y su relevante trabajo La anécdota en la crónica de Indias. Por último entre los narradores contemporáneos, desde los trabajos iniciales sobre Cortázar y Vargas Llosa sus investigaciones han derivado hacia la narrativa de mujeres (Chile), la figura de Elena Poniatowska y un tema específico: los estudios sobre la imagen.

Paradigmático es el pensamiento político de Fernández de Lizardi, que atraviesa distintas fases: desde una solicitud de autonomía respecto al gobierno peninsular que pasa más tarde por la petición de una independencia política pero no religiosa hasta llegar finalmente a la conclusión de una independencia absoluta, unida a una acerba crítica en su Historia de la Iglesia (Correo Semanario de México. Obras Completas. Vol. VI, México, UNAM, 1982).

2

"Perdido su centro de gravedad al mandoble demasiado brusco de las grandes espadas de la Independencia, volvía después de una centuria a su antiguo centro de gravedad, recobrando su equilibrio. Oscuramente advirtió cómo desde la magna epopeya de la Conquista había sido y no había dejado de ser española» (p. 946). Discurso todas luces circunstancial, pero a su vez veraz, puesto que más tarde se refiere a él, y señala frente al crítico de $A B C$, su firme convicción en la realidad de la presencia española en "Sangre de Hispania fecunda» (Obras selectas, Madrid, Caracas, Eds-

\footnotetext{
El descubrimiento y los héroes hispanos en la literatura modernista

ROCÍO OVIEDO PÉREZ DE TUDELA
}

\title{
EL DESCUBRIMIENTO Y LOS HÉROES HISPANOS EN LA LITERATURA MODERNISTA
}

ROCÍO OVIEDO PÉREZ DE TUDELA

La literatura finisecular nos ofrece una alternancia entre la detracción hacia lo hispano, producto lógico de las guerras de la Independencia americana, y el rescate de los héroes que han configurado la historia de España.

Manuel Díaz Rodríguez resumía el antihispanismo que se produce en las antiguas colonias durante el XIX cuando destacaba, en la conmemoración de El Día de La Raza, que el odio hacia España se fundaba en dos circunstancias: la incomunicación real entre ambas orillas y una gestión política deficiente. Fruto de las guerras de la Independencia, los recién creados países necesitaban expresar su diferencia frente a lo que fue la opresión y codicia de la península. Efectivamente, si analizamos la historia de la Independencia y las decisiones que se tomaron desde la regencia de España, no podemos sino afirmar con Díaz Rodríguez que la gestión política de la monarquía y sus sucesivos gobiernos fue absolutamente desafortunada ${ }^{1}$. Despropósitos que tendrán su continuidad en los más cercanos sucesos del 98. Esta situación produce una doble actitud: En el caso de algunos iniciadores como González Prada y modernistas avanzados como Blanco Fombona se repite el rechazo de la acción española. Y, sin embar-

Edime, 1968, p. 818). El 3 pensamiento que expresa Ejemplos de pintura histórica coDíaz Rodríguez coincide mo "La campana de Huesca», con el Preliminar de Darío debida a los pinceles de Casado en Prosas profanas: "Abue- del Alisal se reproducen en La lo, preciso es decíroslo: mi Ilustración Española y Americana esposa es de mi tierra, mi $\mathrm{n}^{\circ} \mathrm{XXXVIIII.}$ amante de París». go, otros escritores como Darío eligen a los héroes españoles como paradigmas.

El momento de la Independencia es, especialmente, un tiempo enriquecedor, como nos recuerda Díaz Rodríguez, pues se entrecruzan con la unidad de la raza el pensamiento europeo y el ideario de la independencia iberoamericana centrado en la libertad y bajo el patrocinio del héroe por excelencia, Bolívar:

Cuando España, después de la independencia, nos volvió la espalda, los iberoamericanos volvimos a todas partes los ojos. Por la raza procedíamos de España, sin duda, pero espiritualmente veníamos también de los enciclopedistas franceses a través de Miranda y Bolívar, a través de aquellos libertadores a cuyos ojos de águila se interponían en vano las fronteras. España sola no bastaba a satisfacer nuestra hambre espiritual².

Tal estado de la cuestión no podía aureolar la figura del Almirante, protagonista de la gesta descubridora y de sus consecuencias, tan denostadas durante la Independencia de las colonias. $\mathrm{Y}$, sin embargo, otros hechos confluyen para ocasionar un ligero cambio de actitud y una recuperación de los héroes hispanos. En primer lugar el patriotismo que promueve el Romanticismo y que encuentra su justificación histórica en la invasión napoleónica. Supone una corriente de revisión de la Historia y una recuperación de los mitos como Colón o El Cid. En segundo lugar la tendencia historicista de la pintura, presente desde fines del XVIII, se divulga a través de los grabados en el periodismo ${ }^{3}$. Pintores 
como Villaamil, Benito Mercadé o Ignacio Pinazo defienden, a través de sus cuadros, un patriotismo simbolizado en los mitos históricos que conviven con la valentía de los héroes más contemporáneos de la guerra de la Independencia españolat. El mismo José Martí no presenta un rechazo de la conquista, sino de la invasión napoleónica, repetida en Versos libres ${ }^{5}$ y en Versos sencillos, seguramente marcado por su vivencia aragonesa: «Para Aragón, para España/ Tengo yo en mi corazón/ un lugar, todo Aragón/ franco, fiero, fiel, sin saña» ${ }^{6}$. Y en tercer lugar contribuyen a fomentar la vertiente heroica dos acontecimientos: La celebración del IV Centenario y los sucesos del 98. La figura de Colón sazona con singular insistencia los ensayos y los discursos al uso de la celebración. Cánovas ante las repetidas críticas de los escasos esfuerzos llevados a cabo para su conmemoración, convoca veladas, sesiones culturales, y promueve la restauración del Monasterio de la Rábida ${ }^{7}$.

Durante el Modernismo la perversidad que se le atribuye posteriormente en la novela del «boom» se mantiene atenuada. Las causas se pueden encontrar, entre otras, en el Romanticismo que fagocitó la recreación de las escenas medievales y en el contenido utópico del pensamiento colombino. Un movimiento que, frente al academicismo neoclásico precedente $^{8}$ "aspiró a la diversidad y particularidad estilística con la vista puesta en los distintos períodos de la historia». El espíritu heroico se traduce en el concepto del honor y la lealtad escenificados en el drama histórico, que tan caro fue a los poetas españoles.

La gesta de la independencia americana se conjuga con la tendencia heroica de la época que se impone desde el pensamiento político y filosófico. Rodó y Blanco Fombona repiten las calificaciones que Nietzsche atribuye a lo heroico. De hecho, el decadentismo, propio del nihilismo nietzscheano, matiza que el rescate de los héroes ya pertenezcan al medievo o al renacimiento. Decadentismo que finalmente resemantiza la recuperación de la Historia y sitúa al Modernismo en la senda del pensamiento melancólico. La crisis que vive la península forja, en este momento, la añoranza, $\tan$ claramente perceptible en Las sonatas de Valle Inclán. La Edad Media, época predilecta del Romanticismo y objeto de estudio de los eruditos ilustrados, brinda héroes signados por el binomio éxito/ fracaso como Colón o El Cid, paradigmas de libertad en los complejos momentos de la invasión napoleónica, y afirmación del heroísmo popular.

\section{MELANCOLÍA, UTO- PÍA, HEROÍSMO}

Este contexto favorece la reiteración de tres personajes singulares en el Modernismo: Colón, El Cid y Cervantes. Antes de localizar los textos en los que los modernistas hispanoamericanos les citan, creo conveniente hacer un

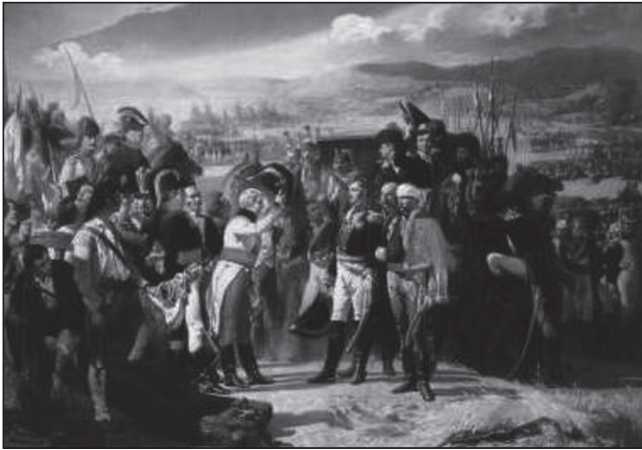

Casado del Alisal. Rendición de Bailén.

breve inciso sobre cómo el

movimiento finisecular lleva a cabo la recuperación de los héroes, en términos a los que ya he aludido anteriormente: la situación histórica que vive la península se aviene con los calificativos más comunes atribuidos a Colón y que pasamos a analizar: heroísmo/cobardía, melancolía y utopía. Añoranza y melancolía, frutos del decadentismo, asentados en el tiempo de un pasado perdido, como nos indica su símbolo más reiterado, Saturno. El sentimentalismo nostálgico del romanticismo se troquela en el modernismo a través de la original concepción de la recreación del pasado (Ricardo Gullón ${ }^{9}$ ). Un tiempo en el que se entronca la representación colombina del modernismo.

La recreación del pasado supone una variante derivada del tiempo nostálgico y sentimental de los románticos. Comparten Romanticismo y Modernismo la singular predilección por la recuperación de lo perdido, con una diferencia esencial: los románticos «añoran» el pasado y lo lloran. La imitación romántica del pasado más que fiel retrato del momento que representan tiende a retratar el sentimiento de la época concreta a la que hacen referencia. Por el contrario, el Modernismo refleja un espacio y más concretamente el pensamiento modélico sobre el que proyectar su propia concepción, objetiva y a

4

La toma de Bailén, los Fusilamientos del dos de mayo (Los desastres de la guerra, de Goya) son acontecimientos históricos que pueblan las imágenes pictóricas con representación de los dos bandos. Asimismo A. de Beruete disertará sobre el tema en El cuadro como documento histórico. Madrid, 1922. J. Caveda le había precedido con su La poesía como elemento de la historia. Madrid, 1852. Cf. Carlos Reyero, «lconografías representativas, verosímiles y verdaderas. Problemas de la recuperación visual del pasado en la pintura española del siglo XIX», Cuadernos de arte e iconografía. FUE, II: 4 (1989), en http://www.fuesp.com/revistas/pag/cai0456.html

\section{5}

En torno al mármol rojo en donde duerme/ el coso vil, el Bonaparte infame /.../... las banderas/ de tanto pueblo mutilado y roto/ en pedazos he visto ensangrentadas» («En torno al mármol rojo». Versos libres, en José Martí, Poesía completa Madrid, Alianza, 1995, p.150).

6

Y la referencia más directa a la guerra de Independencia española con la que obligadamente debía sentirse identificado: «Allá, en la vega florida/ la de la heroica defensa,/ por mantener lo que piensa/ juega la gente la vida. // Y si un alcalde lo aprieta/ o lo enoja un rey cazurro/ calza la manta el baturro/ y muere con su escopeta /.../ Estimo a quien de un revés / echa por tierra un tirano: / lo estimo, si es un cubano; /lo estimo, si aragonés» (VII, Versos sencillos en ibid., pp. 173-174).

7

Pero no acalla las lenguas maldicientes que afirman que el Descubrimiento ha sido más celebrado por los Estados Unidos que por España.

8

Al que García Melero define como «el absolutismo del arte que buscaba la unidad y la universalidad, basándose en la recreación del código clásico» (Arte español de la ilustración y del siglo XIX. En torno a la ima gen del pasado. Madrid, Eds Encuentro, 1998, pp. 4-5).

Ricardo Gullón, Direcciones del modernismo, Madrid, Alianza ed., 1996.

\footnotetext{
El descubrimiento y los héroes hispanos en la literatura modernista

ROCÍO OVIEDO PÉREZ DE TUDELA
} 


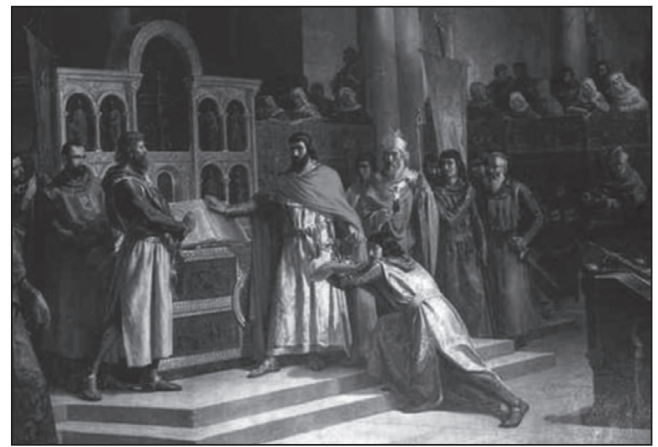

Jura de Alfonso VI en Santa Gadea. Hiráldez Acosta.

su vez histórica, ajena al sentimentalismo. Este original tiempo indica que los personajes históricos serán «recreados», como ocurre con el famoso cuento «La muerte de Salomé» de Rubén Darío. Sin embargo, esta recreación concreta de personajes históricos desaparece en José Martí. En el poeta y liberador cubano tan sólo surge el concepto de lo caballeres-

10

"Odio el mar», Versos libres, en Poesía Completa, op.cit., p. 136 «A Néstor Ponce León», p. 508.

11

La presencia de El Cid en la literatura romántica es constante. No resulta extraño que Manuel Machado lo seleccione para su expresión del decadentismo, se le había anticipado Hartzenbusch en La jura de Santa Gadea también presente en la pintura obra estrenada en el teatro de $E I$ Príncipe en 1845

12

A través de la cita de García Gilbert, Cervantes y la melancolía. Valencia, Novatores, 1997 (Cervantes refleja en su obra "el estado agridulce del autoconocimiento, del revelador y lúcido desengaño»), pp. 123-132.

13

José Enrique Rodó, Ariel, introd., y notas Belén Castro Morales, Madrid, Cátedra, 2000, pp. 181-183

\section{4}

Fernando Ainsa indica que el pensamiento utópico desincroniza los tiempos y convierte el transcurso en cronotropo ( $L a$ reconstrucción de la utopía. Buenos Aires, Eds. del Sol, 1999).

15

Aristóteles, El hombre de genio y la melancolía. Problema XXX. I. prólogo y notas de Jackie Pigeaud; traducción de Cristina Serna, Barcelona, Quaderns Crema, 1996. Según Aristóteles la melancolía caracteriza a los grandes hombres y se manifiesta en una exacerbación de la embriaguez y la lujuria. La

co en una amplia acepción que elimina los héroes concretos. Una abstracción que abarca su contrario, el término tirano. La única referencia que permite adscribirle a la crítica de la conquista en su poesía surge de conceptos muy genéricos, como ocurre en «A Néstor Ponce León» o en «Odio el mar»

Odio el mar que sin cólera soporta

Sobre su lomo complaciente, el buque

Que entre música y flor trae a un tirano ${ }^{10}$

¿Por qué no surge la recreación del pasado en Martí ni para ceñirse a ella ni para denostarla? La razón es sencilla, su interés se centra en la actualidad, se encuentra movido por un presente que no le permite ninguna distracción. No busca nostálgicamente traer el pasado a un presente, sino la urgencia de hacer realidad un tiempo nuevo.

La historia, por tanto, se escribe de forma diferente, de acuerdo con la situación particular de cada autor y de cada país de origen. Los héroes hispanos desaparecen para dar paso a símbolos que abarcan un amplio abanico de acepciones y forjan un concepto personal sobre la historia: Rubén Darío, Santos Chocano, Guillermo Valencia, Amado Nervo, Jaimes Freyre, Blanco Fombona, etc. coinciden en enfatizar la labor negativa y a veces nefasta de los colonizadores, pero también en ocasiones digna de elogio, con el ejemplo de Las Casas al frente.

Pese a las posibles polémicas tres figuras preservan y mantienen el concepto heroico

genialidad responde al «furor poético» o exaltación del espíritu dionisíaco. En «La hoja de oro», (Prosas profanas) Darío se hace eco de esta relación pues la hoja dorada evoca «la autumnal tristeza de las vírge- nes locas,/ por la Lujuria, madre de la Melancolía».

16

Roger Bartra, Cultura y melancolía, Barcelona, Anagrama, 2001. del hispanismo: El Cid, Colón y Cervantes ${ }^{11}$. El rasgo común a este triunvirato de personajes histórico-literarios se encuentra en un eje: los tres mantienen un alto nivel de aspiraciones, alcanzan la gloria en un momento de su existencia, pero los tres son víctimas finalmente de su sociedad, o de lo imposible de su empresa, que frena, en definitiva, sus aspiraciones. Símbolos del pensamiento melancólico como veremos a continuación.

La melancolía se aviene con el espíritu heroico, afirma G. Fernández Ariza, quien enfatiza en la obra de García Márquez y Carpentier la bisagra cervantina que amalgama pensamiento heroico y melancolía ${ }^{12}$. En el Modernismo se adopta el concepto de heroísmo que expone Carlyle en su ensayo Los héroes (1840): el héroe es aquel personaje que logra aglutinar a la sociedad y orientarla frente al caos y la decadencia, precedente romántico de su homólogo: el superhombre nietzscheano. La relación entre ambas teorías la confirma el hecho de que, en Ariel, José Enrique Rodó interpola la cita de Carlyle junto a Nietzsche, para refrendar la simbiosis entre heroísmo y melancolía ${ }^{13}$. Conceptos que se incardinan en otro que asume la efigie de Colón: la utopía, definida por Fernando Ainsa ${ }^{14}$ como desajuste temporal, tal vez una inversión que favorece la conversión del pasado en recreación.

La utopía y la melancolía son cualidades distintivas del héroe y mantienen una estrecha relación con el concepto de genialidad y creatividad $^{15}$-vertiente creativa en la que se entrevera la utopía-. Según Roger Bartra ${ }^{16}$, es una manifestación más del alma barroca, y su gran representante será el loco de los locos, don Quijote. Los modernistas, a su vez barrocos, proyectan sobre Colón, Cervantes o el Cid, su concepto del espíritu melancólico. Y en concreto José Enrique Rodó aglutina la figura del superhombre y del héroe en Bolívar. Auténticos hombres geniales se adaptan al espíritu dionisíaco que Nietzsche atribuye a lo heroico.

Predecesor de los modernistas, el filósofo alemán, en un poema homónimo, - «Melancolía»-, recoge de la tradición del «furor poético» el emblema de Prometeo. De esta tipología de caracteres expuesta por Platón y Aristóteles, sin duda le atrajo la caracterización de la genialidad, que aplica a su Superhombre. En el poema y en Así hablaba Zaratustra, extrapola la cualidad melancólica e indica que su manifestación es el hastío, consecuencia de la incapacidad de salvar el 
presente en un futuro, fruto del tiempo. Al igual que Saturno devora a sus hijos, el tiempo se detiene y la vida se convierte en una pesada carga. El sentimiento melancólico añade el hecho de quedar lastrado por la cercanía de los detractores cuya presencia determina la caída en el hastío ${ }^{17}$. La crítica y la amenaza se ciernen sobre el escritor desde un mundo cercano, como advierte Nietzsche ${ }^{18}$. Guillermo Valencia se hace eco del emblema más característico de la melancolía en su poema: «Un grabado de Durero», en el que presenta el concepto de voluntad nietzscheano junto con la utopía:

despiertas/ las visiones muertas/ que forjó el Anhelo/... « La kábala, eximia/ los trozos de Alquimia / fatigan la alfombra/¿Es debil gemido/ que anuncia el olvido/ o símbolo oscuro / que cifra el futuro? / ¿Es oculta clave del amor humano,/ o el jay! del gusano/ que quiso ser ave? ${ }^{31}$.

\section{COLÓN, EL CID, DON QUIJOTE EN LA POESÍA MODERNISTA}

Frente a la preferencia de Darío por el Almirante, Amado Nervo y Blanco Fombona reparten su protagonismo con fray Bartolomé de Las Casas y Hernán Cortés. Actitudes antagónicas que entrechocan y bipolarizan la acción conquistadora.

Colón, sin embargo, se queda a medio camino. No es español ni americano, y sin embargo su procedencia le hace desfilar entre la independencia política y la sumisión al gobierno español. Con frecuencia puede aparecer junto al rey navegante, el portugués Don Sebastián, como ocurre con Santos Chocano y Blanco Fombona. Es un caso especial que no siempre puede ser utilizado como reflejo de las críticas o de las alabanzas. Incluso en su obra El conquistador español del siglo $X V I$, Rufino Blanco Fombona advierte: «Se ha criticado mucho y con sobra de justicia, el sistema de encomiendas, no lo inventó un español, sino un italiano: Colón».

Variantes de esta actitud de los conquistadores nos la ofrece Díaz Rodríguez quien comparte con los contemporáneos españoles el interés por los tiempos de la conquista y su deseo de ver convertidos en literatura los acontecimientos de esos momentos tan decisivos de la historia: «En el verso y la prosa nuevos no se han visto reflorecer como debían el milagro de la conquista, ese milagro único, ni los días claros o turbulentos de la colonia» 20 .

La rebelión ante la monarquía ocasiona la elección de la figura del Cid como símbolo de la libertad y a su vez de la nobleza que piden para sí los nuevos pueblos americanos. Guillermo Valencia combina en su poema «Himno de la raza» la actitud de los conquistadores y la de Rodrigo Díaz de Vivar y los enfrenta como símbolos antagónicos. Sobre la palabra que inicia el descubrimiento, «Tierra» 21 , construye un verso donde el Cid, de ser protagonista, se transforma en un calificativo más: «iTierra!/Tierra buena que acoges al hombre/.../ Mundo nuevo que ciñen dos mares/ premio fuiste al valor y a la $\mathrm{fe/Lentos} \mathrm{años} \mathrm{mordió} \mathrm{la} \mathrm{violencia} \mathrm{/} \mathrm{razas}$ tuyas de ignoto vivir, / y otra vino a vengar el agravio / sobre el fiero caballo del Cid».

Sorprende en el texto su interés por la adecuada interpretación del poema, hasta el punto de insertar anotaciones finales que completen su significado. Un ejemplo lo tenemos en el término «Tierra» palabra con la que se inicia la conquista y que, según el autor es una referencia al 12 de octubre. Y aprovecha para interpolar un tema candente en estos momentos: la necesidad de un panamericanismo que se trata de promover en las distintas conferencias interamericanas. Sus explicaciones del poema avalan la hermandad de los pueblos hispanos: «A la unidad continental solo podrá llegarse por el mutuo afecto, la cooperación, el generoso obrar con los vecinos»22. Armo-

\section{7}

En el caso de Amado Nervo, conserva los caracteres aplicados por Nietzsche al espíritu melancólico: hastío y cita del espíritu saturnal: "Sí: ¡la vida es mal! Pero la vida/ No concluye jamás. El dios que crea, / Es un esclavo de otro dios terrible/ que se llama Dolor. $Y$ no se harta/ el inmortal Saturno! jY el espacio, / el vivero de soles, lo infinito, / son la cárcel inmensa, sin salida,/ de almas que sufren y morir no pueden/ ¡Oh Saturno inflexible, alfil acaba, / devora lo creado y rumia luego /...../ Somos tuyos Dolor, tuyos por siempre/ mas perdona a los seres que no existen/ sino en tu mente que estimula el hambre/
¡Perdón, oh Dios, perdón para la nada! / sáciate ya, ¡Que la matriz eterna, / engendradora del linaje humano/ se torne estéril ... que la vida pare.../ ¡Y ruede el mundo cual planeta muerto/ por los mares sin olas del vacío» (Obras completas. Madrid, Aguilar, p. 232)

18

"Avido el buitre graznaba en el valle, /soñándome carroña sobre madera muerta. $/ \mathrm{j} T \mathrm{Te}$ equivocaste pájaro devastador,/ aunque momificado descansara en mi leño!/ No viste mi mirada llena de placer/ pasear en derredor altiva $y$ ufana;/ y cuando insidiosa no mira a tus alturas, / extinta para las nubes más lejanas, se hunde en lo más profundo de sí misma/ para radiante iluminar el abismo del ser. /amiga mía, te complaces en manifestarte a mi alrededor / y en mostrarme amenazante el rastro del buitre y el goce de la avalancha para aniquilarme./ En torno a mi respira enseñando los dientes/la apetencia de muerte:/jtorturante avidez que amenaza la vida /.../ Y yo aquí estremeciéndome balbuceo canto tras canto /y me convulsiono en rítmicas figuras:/fluye la tinta, salpica la pluma afilada, /ioh diosa, diosa déjame - déjame hacer mi voluntad!».

19

Guillermo Valencia, Obras poéticas completas, Madrid, Aguilar, 1955, p.76

20

"A la entrada de un bosque virgen» (1906), en Obras selectas, Madrid, Caracas, Eds. Edime, 1968 , p. 775 . En alabanza a Chocano que ha sido el primero en atreverse a introducirlo en su obra.

21

"Himno de la raza» y "Anotaciones», en Obras poéticas completas, op. cit, pp. 443- 453.

22

«Polvo fugaz quitóles el hado adverso/ más tú, Señor entre conquistadores / al sucumbir.. perdiste el Universo».

\footnotetext{
El descubrimiento y los héroes hispanos en la literatura modernista

ROCÍO OVIEDO PÉREZ DE TUDELA
} 


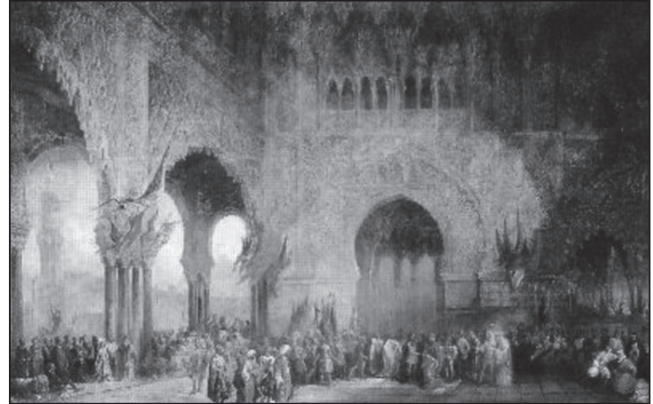

El juramento de Alvar Fáñez. Minaya. nización política que ya se encontraba prefigurada en el ensayo de José Martí y cuyo esencial paradigma serán los héroes de la independencia americana.

El Cid se suma a Don Juan y a Don Quijote como antecedente de Bolívar en el ya citado discurso de «El Día de la Raza» de Díaz Rodríguez. El libertador venezolano es un 23 Díaz Rodríguez, op. cit., pp. 950-951. La continuidad de este discurso se encuentra en "Sangre de Hispania fecunda» en el que se asombra de la parvedad de que dan muestra los escritores «Parece como si tales escritores tan solo hubiesen tomado de sus colegas transpirenaicos el mentecato nacionalismo de última hora, que estuvo a punto de sofocar el alma del pueblo francés» y añade " En un brusco ademán de sentimentalidad irritable y herida, España se volvió de espaldas a América: la desconoció, la negó, la ignoró, afectando actitud candorosa de quien rehuye mentar al adversario, como si con el solo hecho de callar su nombre la suprimiera de la naturaleza y de la vida» (pp.808-809).

24

Emilio Gasco Contell, José Enrique Rodó. Estudio y antología "De Bolivar». Madrid, Cía Bibliográfica española, 1970, p 105.

25

Convoca en 1826 al Congreso Internacional de Panamá, "con el fin de echar las bases del derecho público americano y erigir, a pesar de los celos locales, el gran poder Iberoamericano, la Sociedad de Naciones》 y añade «El hombre de genio veía entorpecidos sus planes por microbios a quienes despreciaba: Santander en Cundinamarca, Rivadavia en Argentina, Páez en Venezuela, Freyre en Chile. Pero aquellos microbios eran una gran fuerza: representaban, sin saberlo, el espíritu de la raza» (El conquistador español,

\footnotetext{
El descubrimiento y los héroes hispanos en la literatura modernista

ROCÍO OVIEDO

PÉREZ DE TUDELA
}

ejemplo de la tenacidad de la raza, semejante -añade- a la de los antepasados de la reconquista y «trasunto de cuanto hay de justicia y de belleza en la figura ideal del Quijote (...) Bajo la seducción románico española del don Juan, vivió la plenitud de la vida caballeresca y heroica del Cid. Y también, como el Cid, sigue librando y ganando batallas por nosotros más allá de la muerte» ${ }^{23}$.

Bolívar es un reiterado modelo, del que, a su vez, se sirve Rodó, buscador infatigable del imposible panamericanismo: «será siempre el héroe por excelencia representativa de la eterna unidad hispanoamericana» ${ }^{24}$. Palabras que le unen a la red de admiradores de Bolívar como Blanco Fombona ${ }^{25}$. El venezolano finalmente establece un vínculo entre él y el espíritu quijotesco: «El Don Quijote en carne y hueso» que fue Bolívar, en su lecho de muerte, define su fracaso y repite las palabras pronunciadas por el libertador: «Jesucristo, don Quijote y yo, hemos sido tres grandes majaderos» ${ }^{26}$.

El ejemplo de los libertadores heroicos encuentra su eco más encomiable en la poesía de Santos Chocano, El canto del siglo. Poema finisecular, publicado para celebrar el pasado ante el nuevo siglo (1901), descubre en una plástica y parnasiana descripción, el sueño de Bolívar en los relieves de una figura esculpida: en Escritos políticos. Caracas, Ayacucho, p. 19). Su interés por la figura del libertador se completa en su obra Las mocedades de Bolivar, Caracas, $M^{\circ}$ de Educación Nacional, Dpto de Cultura, 1945, y en su ensayo, "El espíritu de Bolívar», incluido dentro de sus Escritos políticos.

26

Op. cit., p. 25
27

Díaz Rodríguez, op. cit., pp. 691 y 694

28

Op. cit. p. 811

29

«Bajo la luminosa, nocturna estela/y entre la polvareda de los caminos, en busca de Santiago de Compostela/pasan, cantando salmos, los peregrinos".
Y Bolívar aguárdalo en acecho

Cual firme gladiador: la frente erguida

Uno tras otro pie, salido el pecho,

Es un titán que en épica apostura

Representa la lucha por la vida (p. 285)

La acción libertadora politiza el descubrimiento en el hoy y lo actualiza, de forma que mediante la recreación del pasado, adapta en provecho propio la experiencia anterior y la crítica. Aprender del pasado, como enfatiza Guillermo Valencia, es una variante más de las acepciones sobre la historia y la conquista. Un ejemplo que funciona como molde que encontramos en los poemas juveniles de Rubén. La asamblea de la Unión Centroamericana, nos brinda el germen de su insistente énfasis en la unidad de los pueblos, que se repite en sus últimas obras: «La 'medusa' de fuego / que se llama Discordia, sin sosiego/ atiza el horno de pasión artera» (p. 82).

Las posibilidades de transformación animan a Díaz Rodríguez a escribir otros dos poemas referidos a la Conquista: «Pregón del Conquistador» ${ }^{27}$ y «Segundo Pregón del Conquistador». El tono didáctico y el rechazo de los errores de la conquista se imponen sobre el contenido anecdótico. Pero lo que es más interesante es la constante actualización del pasado: en cita de Rodó sobre su propia obra (Camino de perfección) se reafirma en el concepto de "primitivismo» que ambos atribuyen a la raíz española «en vez de pueblo degenerado como tontamente proclaman algunos, del pueblo español puede afirmarse más bien que es pueblo primitivo» ${ }^{28}$.

Las críticas alternan con la aceptación de la herencia hispana y Jaimes Freyre recupera el pretérito con la firme convicción de actualizarlo en el hoy. En «Los antepasados» asume sus raíces:

Hijo soy de mi raza; corre en mis venas sangre de los soberbios conquistadores. Alzaron mis abuelos torres y almenas; celebraron su gloria los trovadores.

Su poesía se adentra en el enigma de Colón. El hálito del misterio se intensifica al localizar la acción en Santiago de Compostela. El poema se jalona con citas literarias en las que Berceo se codea con Trotaconventos, Alfonso X, el conde Alarcos o el Arcipreste de $\mathrm{Hita}^{29}$. Sumergido en lo ignoto, propio de la melancolía, como vemos en el primer poema, a Colón le corresponde cerrar con estos 
versos los signos propios: libertad, espíritu heroico e individualidad.

Librado a los destinos y a los azares, de espaldas a la vida, de frente al cielo, tiende Colón sus alas sobre los mares, como un ave gigante que emprende el vuelo ${ }^{30}$.

El espíritu heroico que domina en la poética de Jaimes Freyre, adopta el imaginario que asistía a las descripciones de la melancolía, la mirada infinita, la imagen del guerrero y los pájaros que se ciernen amenazantes contra el héroe, y que coinciden con la imagen proporcionada por Nietzsche:

Aún se estremece y se yergue y amenaza con su [espada cubre el pecho destrozado su rojo y mellado escudo hunde en la sombra infinita su mirada y en sus labios expirantes cesa el canto heroico y [rudo.

Los dos Cuervos silenciosos ven de lejos su agonía y al guerrero las sombras alas tienden

y la noche de sus alas, a los ojos del guerrero, resplandece como el día

y hacia el pálido horizonte reposado vuelo emprenden ${ }^{31}$.

Dos poetas se suman a la nómina de escritores que enfocan los años del descubrimiento: Amado Nervo y Santos Chocano.

El poeta mexicano, sentencia en «El gran viaje» el desacierto de la conquista y de los conquistadores. Y sin embargo, frente a ellos se erige el modelo de Colón, quien desplaza en interrogaciones el futuro de un tiempo lastrado por la crisis finisecular.
¿Quién será, en un futuro muy lejano,
el Cristóbal Colón de algún planeta?
¿Quién logrará, con máquina potente,
sondear el océano
del éter, y llevarnos de la mano
allí donde llegaran solamente
los osados ensueños del poeta?

En las últimas estrofas Amado Nervo interpela a las futuras generaciones y al progreso que puede traer una gesta de las dimensiones que adquiere la colombina.

¿Quién será, en un futuro muy lejano, el Cristóbal Colón de algún planeta? ¿Y qué sabremos tras el viaje augusto? ¿Qué nos enseñaréis, humanidades de otras orbes, que giran en la divina noche silenciosa, y que acaso hace siglos que nos [miran?

La mirada que proyecta sobre la figura colombina está marcada por el heroísmo. Frente a Blanco Fombona que, como vimos, afirmaba el carácter italiano de Colón, Nervo expone su raíz española, con motivo del traslado de sus restos tras el desastre del 98: «aun cuando nació en Italia, fue español: Isabel hizo florecer su genio (...). Y no sólo era español Colón; era más; era el símbolo de la España audaz y conquistadora de los siglos XV, XVI y XVII; de la España heroica, de la España caballeresca y pródiga de energías y de sangre...»32.

La actitud de Nervo hacia la conquista se completa con dos poemas «Hoy» $\mathrm{y}$ «Ayer», en los que recupera el pasado pre y poscolombino, bajo el epígrafe común de La raza muerta (1896): El primero actualiza «La fiesta santa de Quetzalcóatl», en la que el rey medita sobre los augurios fatales del «Dios serpiente»: «Y entonces en un vuelo de naves del Oriente/ vendrán los hombres blancos, que matan con centellas». El futuro se abre paso en Anáhuac, donde «Triunfa Spencer, muere Aquino; cae un mundo, un mundo brota.../ ¡Todo es vida y esperanza!/ Solo el indio trota, trota/ con el fardo a las espaldas y la frente en las tinieblas» ${ }^{33}$.

Frente a la utopía americana, se alza el error de la conquista. Pero no sólo el continente americano resulta perjudicado, sino que, indica Rodó en «El camino de Paros», perjudicó también al reino de Aragón, como explica un joven estudiante ante la estatua de Colón:

Inmensa es la gloria de Colón, e indiscutible la belleza de este monumento, pero nunca se presentará mejor ocasión de recordar el non erat hic locus de Horacio (...) Colón no debiera estar aquí. Su estatua quedaría mejor en cualquier otra de las ciudades de España. Cierto que es que aquí desembarcó, trayendo en la mano el orbe de oro que puso en las de Isabel y Fernando; pero, en la parte referente a nosotros, ¿̇representó esto un beneficio. El espléndido obsequio de Colón fue de gloria para la humanidad, de gloria
30

«En esa sangre hay ondas rojas y azules;/es de un solar mi escudo lustre y decoro. (En cambo de sinople, faja de gules/ engolada de fieros dragantes de oro).

31

"La muerte del héroe», en Amado Nervo, Castalia bárbara y otros poemas, prólogo de Leopoldo Lugones, México, Cultura, 1920.

32

"2 de octubre de 1898», en Obras Completas. Tomo I. Madrid, Aguilar, 1962.pp. 867. En el artículo «25 de septiembre de 1898», escribe un singular resumen de su concepto de lo heroico: el «lote común» a los héroes es «la voluntad y la fe» y añade «La voluntad es todo, la voluntad lo puede todo (...) nada hay más lamentable e ignominioso que esta enfermedad moderna: la impotencia moral, caracterizada por Shakespeare en Hamlet, en Hamlet que razona y que ya no puede querer» (ibid., p. 865). $Y$, por supuesto, en paralelo con sus contemporáneos el héroe por excelencia será siempre Bolívar.

33

Poesías completas. Barcelona, Teorema, 1982.

\footnotetext{
El descubrimiento y los héroes hispanos en la literatura modernista ROCÍO OVIEDO PÉREZ DE TUDELA
} 


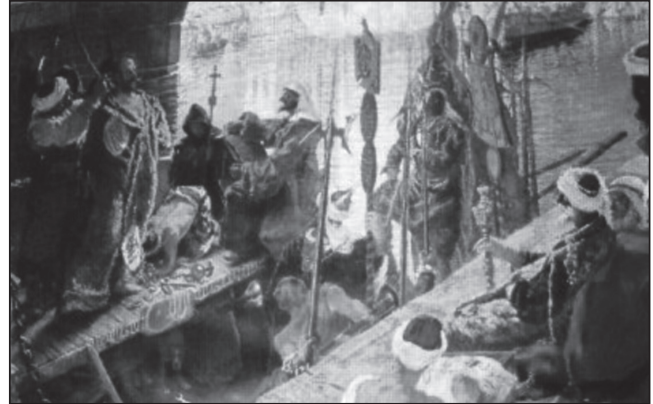

Cervantes en Argel. Muñoz Degrain.

34

El camino de Paros, p. 88.

35

En El conquistador Español, afirma que los españoles no le dan importancia a las maravillas del Nuevo Mundo, pero se interesan por el oro. Su actitud individualista promociona la guerrilla y e caudillaje que finaliza en tiranía, como expone en su capítulo «Dureza de la raza». Estrada Cabrera se une a la nómina que había encabezado Rosas, Facundo Quiroga, Juan Vicente Gómez, Portales (Chile), García Moreno (Ecuador) o Francisco Solano López (Paraguay).

36

En Madrid, por aquel tiempo 1819, la reacción triunfante asume la actitud de D. Quijote, «molido a palos y hablando de exterminar» (p. 24)

37

La lírica se hace eco de la crítica historiográfica que aún discute si realmente los Reyes Católicos eran conscientes del alcance de las exigencias colombinas, cuando firmaron las Capitulaciones de Santa Fe (Cf. los trabajos de Consuelo Varela).

38

"Aún los mejores, entre los hombres de descubrimiento $y$ conquista, tuvieron la sed y el hambre del oro. Colón mismo no podría ser exceptuado» (op. cit. pp. 27-28)

39

Ibid., p. 90. Más adelante, en la Segunda Parte, al abordar a los conquistadores señala que son movidos por la rapiña, al tiempo vanidosos y sobrios, «despóticos y democráticos, individualistas y religiosos, corajudos y fatalistas. Vengativos, duros, amigos de

\footnotetext{
El descubrimiento y los héroes hispanos en la literatura modernista

ROCÍO OVIEDO PÉREZ DE TUDELA
}

y grandeza para España; para Cataluña fue el triste presente de la decadencia. A Cataluña le hirió, si no en el corazón, en las vísceras del vientre. Éramos súbditos del Mediterráneo; el Mediterráneo era la vía del intercambio universal. Compartíamos con las ciudades italianas, con Venecia, con Génova, el dominio de las rutas que llevaban fuera de Europa. Todo esto desapareció desde que fue transportado al Atlántico el ejercicio comercial del mundo; nos hundimos en la despoblación y la pobreza ${ }^{34}$.

Las luces y las sombras de la gesta descubridora tienen su más dilatada expresión lírica en Alma América de Santos Chocano. En paralelo con sus correligionarios, proyecta una escritura de la Conquista como conglomerado de sueños y realidades encabezados por la utopía colombina: «Colón puso el delirio de su mente;/ pero la realidad ... la puso España». La repetición de las citas sobre los conquistadores y su percepción de la península en su mejor versión de «Madre Patria», no elimina la crítica a la codicia de los españoles. Ni tampoco su crueldad expresada con toda acritud en su Tríptico beroico (Caupolicán, Cuauhtémoc, Ollanta). Se empareja, por tanto, con las calificaciones que Blanco Fombona atribuye como características de la idiosincrasia del pueblo español ${ }^{35}$ y de las que ni siquiera escapa «El Ingenioso Hidalgo", a quien el genio de Cervantes vistió de arrogancia con la célebre frase: «¿Leoncitos a mí?»36.

La amalgama de la leyenda negra y la leyenda áurea construyen su discurso heterodiegético: $\mathrm{Si}$ «El cofre de joyas de Isabel esparce,/ a través de cuatro siglos, su fulgor;/ y tras la conquista de la Media-Luna/ surge la velera conquista del sol», también sobre el Nuevo Mundo de «mares de ventura» y «tierras de misterio» se vierte la semilla de la discordia «celos de Fernando, grillos de Colón». La expresiva cita «Los celos de Fernando» trae a primer plano la principal polémica y juicio sonado del descubrimiento ${ }^{37}$.

ceder a la suerte, más guerreros que militares, imprevisores, intolerantes, carentes de sensibilidad, malos políticos, hombres de presa, etc.» ( $p$ 98). La alabanza alterna con la crítica pues páginas atrás había calificado de "festín de antropófagos» el hecho de consumir jamón, calificado de "carne cruda».

40

Ibid., p. 131
Frente a los detractores de la acción conquistadora, la «Crónica alfonsina» desarrolla una singular teoría del «encuentro» en la que Dulcinea, símbolo de la cultura hispana, y Jimena, indígena, pues lleva plumas, ofrecen una simbiosis de conocimiento y experiencia. Ambas dan la mano a los singulares héroes literarios: Don Quijote y Don Rodrigo. De este modo lo literario y lo histórico configuran la mirada que se proyecta en la conquista y contagia con los signos de la realidad y el onirismo el futuro, signado por lo real maravilloso.

La literatura se hace eco de la poesía heroica que es la «poesía más espontánea de la lengua» española en opinión de Blanco Fombona. Y, sin embargo, el más soñador de los descubridores no escapa a la seducción del oro $^{38}$. Se describe, por tanto, al pueblo español como pueblo de actuación paradójica: Carece de sentido práctico pero «ha sido el pueblo de la acción generosa, del ocio romántico, del desprecio caballeresco al utilitarismo térre a térre. Ha sido un pueblo de caballeros, de santos, de héroes. Hasta el mismo Sancho Panza representante del espíritu práctico español, resulta un idealista» ${ }^{39}$. Una barbarie que se aviene con la actitud de Guzmán el Bueno y el Conde Alarcos.

Frente a la barbarie, el ya manido concepto de la civilización se esgrime como factor decisivo del «espíritu civilizador» de las Leyes de Indias. Leyes que son la senda por la que deambulan figuras como Bartolomé de las Casas «honor de España». Protagonista ejemplar que se anticipa a su tiempo por filántropo y humanista, frente al fanatismo. Enfrentado a la acción destructiva de la conquista es el ejemplo de quien se sitúa «al lado del débil contra la fuerza, de la bondad contra el rigor, la justicia contra la opresión $»^{40}$.

\section{RUBÉN DARÍO Y LOS HÉROES HIS- PANOS}

Rubén Darío resulta ser un excelente paradigma de la evolución del concepto heroico hispano, centrado en el ejemplo colombino, puesto que la figura de Colón permea toda su trayectoria literaria. Si he acentuado el concepto de melancolía se debe, entre otras causas, a que bajo esta imagen reescribe, recrea Darío a sus héroes. En sus inicios Darío viste con el ropaje característico de los tristes, la bilis negra, a los tres personajes históricos españoles que comparten con Hugo, Baudelaire o Verlaine el parnaso poético: Cervantes, 
Colón, El Cid, de forma accidental Lope o Góngora, como también lo fue Goya o Valle-Inclán. La paternidad de la presencia y la insistencia en la figura de Colón por parte de Darío puede tener su origen en la influencia de Ramón de Campoamor, cuyo drama lírico «Colón» ${ }^{41}$ viste de heroísmo la historia. En los inicios literarios del poeta nicaragüense la figura se consolida como imaginario melancólico, si bien, como veremos, finalmente se convierte en un original modo de calificar.

En «Ingratitud» la imagen del grabado de Durero se conjuga con la presencia de la reina que acompaña al Almirante: «El libro en la mano, la cabeza pensativa». La conjugación de los tiempos sugiere la admiración de la reina por su inspiración melancólica: «Con un libro entre sus manos, / con un mundo en su cabeza/ la frente a inclinar empieza/ cansado de esfuerzos vanos. // Por unas joyas Colón/ legó su soñada tierra; para el numen que él encierra/ sólo encuentra admiración» ${ }^{42}$. Y en general, en estos momentos, la cita de Colón no deja de ser una retórica al uso ( $\mathrm{Al}$ Ateneo de León el día de su inauguración»): Milton, Voltaire, Mirabeau, Sucre, Ricarte, Colón, son representantes de un continente como crisol de culturas:

\section{Sucre, Ricaurte, Colón \\ con indecible alegría \\ ellos vienen este día \\ y están en este salón... \\ ¿No los veis? ¡Al corazón \\ llevad, llevad vuestra mano, \\ que su poder soberano \\ os mostrará claramente \\ latidos de un Continente \\ palabras de un ciudadano!43}

El símbolo colombino se intensifica en estos momentos y en «A Don Pablo Buitrago» dibuja una de las ideas que, como indiqué, Nietzsche y Freud trazaban en su dibujo del melancólico, el rechazo y la crítica de los contemporáneos: «Para todo pensamiento/ hay eterno Santo Oficio/.../ ¡La humanidad altanera/ si hay Colones los desprecia;/ y canoniza la necia,/ a quien maldecir debiera» ${ }^{44}$.

La utopía rubendariana parangona su bien más preciado, «El libro», con «la brújula de Colón,/ la palabra de Jesús». Uso retórico y exaltado, metáfora que une a Colón con los modelos más valorados por Darío, incluido Victor Hugo, aunque la justificación sea escuchar o cantar al Momotombo:
Tu voz escuchó un día Cristoforo Colombo

Hugo cantó tu gesta legendaria.

Los dos fueron, como tú, enormes, Momotombo, montañas habitadas por el fuego de Dios.

De mayor interés es un elemento en sí definitivo para el pensamiento melancólico: la tensión para diseñar un futuro, o el deseo, siempre incompleto, de alcanzar lo imposible ${ }^{45}$ : «...es el deseo/ del Genovés intrépido que un día,/ en éxtasis profundo, / a la Iberia potente diole un nuevo mundo» ${ }^{46}$.

El Cid, sin embargo, es quien inaugura nuevamente el pensamiento melancólico de Darío en sus adiciones a Prosas Profanas. Las dos historias narradas en "Cosas del Cid» trasladan la anécdota de lo popular a su leyenda: el mendigo y la niña, la pobreza y la inocencia se conjugan para enaltecer al héroe en el momento más trágico de su fracaso: El cantar del destierro. Fracaso y honor las dos caras de la moneda más reiteradamente atribuidas al espíritu español como lo manifiestan sus modelos. Esta conjugación de opuestos definen a los arquetipos como D. Quijote o Cervantes en la antítesis de la felicidad y la tristeza: «...el destino/ hace que regocije el mundo entero/ la tristeza inmortal de ser divino ${ }^{47}$.

En Cantos de Vida y Esperanza nos encontramos de nuevo con el Almirante, en este caso, a modo de brindis como ocurre en «Al rey Oscar»

por Lepanto y Otumba; por el Perú, por Flandes;

Por Isabel que cree, por Cristóbal que sueña;

Y Velázquez que pinta y Cortés que domeña.

Pero tal vez es más digno de mención cómo paulatinamente Colón pierde, en la Oda «A Roosevelt», su entidad de sujeto para convertirse en calificativo de América: es la «América fragante de Cristóbal Colón, / la América católica, la América española /la América en que dijo el noble Guatemoc...» ${ }^{48}$.

Calificaciones que, en «Marina», se enfatizan pues Colón se convierte en un calificativo de las velas: «Velas de los Colones/ Velas de los Vascos/ hostigadas por odios de ciclones/ ante la hostilidad de los peñascos».

Conforme avanza el tiempo, Colón en la poética de Darío abandona su protagonismo como arquetipo, se aleja de su concepción histórica y se lexicaliza. En La Caravana pasa, Colón es parte del imaginario y se convierte en un elemento más de la trastienda donde encontrar nuevas metáforas. En Dieppe tras recrearse en la figura de una atractiva quin-
41

La presencia de Campoamor es una característica de esta obra inicial dariana.

42 "Ingratitud», Los sollozos del laúd, en Rubén Darío, Poesías completas. Madrid, Aguilar, 1955, p. 15.

43 Ibid., p. 20

44 Ibid., pp. 28-29.

45

Raymon Klibansky, Edwin Panofsky, Fritz Saxo, Saturno y la melancolía. Estudios e historia de la filosofía de la naturaleza, versión española de María Luisa Balseiro Madrid, Alianza, 1991

46 Darío, Poesías completas, op cit., p. 200

47

«Un soneto a Cervantes», Cantos de Vida y Esperanza.

48

También Blanco Fombona subraya el catolicismo de Colón: "Colón mismo no está exento de excesos religiosos. Escribe como el último sacristán. Se presenta en la Corte con hábito de monjeAunque el caso de Colón sirva, quizá como ejemplo de forzada concesión a las preocupaciones del ambiente social. Colón, hombre de ciencia, tal vez judío, era doblemente extranjero en España-por su origen y por sus conocimientos- y tal vez sólo para congraciarse con el medio exagera la nota católica, emulando a los familiares del Santo Oficio» (p.152). Curiosamente, al igual que ocurre con Rodó en El camino de Paros, surge la individuación del reino de Aragón, frente a Castilla: «La aventura de los conquistadores de América en el siglo XVI es la reproducción, a escala gigante, de la odisea aventurera en los países de Oriente, de catalanes y aragoneses, en el siglo XIV. Es el mismo valor ciego que parte confiando exclusivamente en sí, hacia lo desconocido; el mismo afán de lucro y poder, la misma confianza en el azar...» (p. 308). Y concluye: «Raza heroica por un lado, carece por el otro de sensibilidad» (p. 338).

\footnotetext{
El descubrimiento y los héroes hispanos en la literatura modernista

ROCÍOO OVIEDO PÉREZ DE TUDELA
} 
49

Rubén Darío, La caravana pasa, tomo II, edición crítica, introducción y notas de Günther Schmigalle, Managua, Academia Nicaragüense de la Lengua, Berlín, Tranvía, 2000, p. 159.

50

Véase Rosa Pellicer, "Colón y la busca del paraíso en la novela histórica del siglo XX (de Carpentier a Roa Bastos)», América Sin Nombre, 5-6 (diciembre 2004), pp. 181-187.
El descubrimiento y los héroes hispanos en la literatura modernista ROCÍO OVIEDO PÉREZ DE TUDELA ceañera semejante a una sirena, su mirada se detiene en «una robusta anciana, como sacada de no sé qué olvidado cuadro» cuya falda «deja ver las columnas de las piernas cubierta por medias de lana, sobre los duros zuecos, dos bien construidas carabelas en que un Colón de Liliput podría ir a descubrir en Noche Buena no importa cuál América de nacimiento!»49.

Colón gravita sobre el imaginario de Darío convertido en anécdota. Dos poemas del año 1892, uno no publicado y el otro reeditado en El canto errante equilibran la balanza de la Conquista. En «Mensajero Sublime», instaura una extraña simbiosis con fray Bartolomé de las Casas, pues Colón se convierte en «Mesías del indio». Por el contrario las nefastas consecuencias de la Conquista son el epígrafe que encabeza el poema dedicado «A Colón». $\mathrm{Pu}$ blicado previamente en El Heraldo de Bogotá, Darío responde a las circunstancias en las que nuevamente las esperanzas del panamericanismo se disolvían. El fracaso de Colón es un fracaso infinito que se expande a su conquista. Sobre el Colón de Corsario a Almirante que nos presentaba Consuelo Varela, proyecta su máscara de melancolía Darío. Al igual que en el grabado de Durero el fracaso se origina por las extrañas leyes que rigen el universo o por el fatídico azar que el héroe jamás domina.

Desgraciado Almirante! Tu pobre América, tu india virgen y hermosa de sangre cálida, la perla de tus sueños, es una histérica de convulsivos nervios y frente pálida.

Un desastroso espíritu posee tu tierra: donde la tribu unida blandió sus mazas, hoy se enciende entre hermanos perpetua guerra, se hieren y destrozan las mismas razas (...).

Ellos eran soberbios, leales y francos, ceñidas las cabezas de raras plumas; ¡ojalá hubieran sido los hombres blancos como los Atahualpas y Moctezumas!

Cuando en vientres de América cayó semilla de la raza de hierro que fue de España, mezcló su fuerza heroica la gran Castilla con la fuerza del indio de la montaña.

¡Pluguiera a Dios las aguas antes intactas no reflejaran nunca las blancas velas; vieran las estrellas estupefactas arribar a la orilla tus carabelas!
Que más valiera el jefe rudo y bizarro que el soldado que en fango sus glorias finca (...)

Duelos, espantos, guerras, fiebre constante en nuestra senda ha puesto la suerte triste: ¡Cristóforo Colombo, pobre Almirante, ruega a Dios por el mundo que descubriste!

La crítica a Colón es sobre todo una crítica a la fatalidad de la Conquista. Los modernistas asumen la responsabilidad y la tragedia de enfrentar un futuro condenado de antemano por la corrupción. El paraíso se degradó en el infierno.

Colón no volverá a fungir como héroe. $\mathrm{Su}$ acción se invierte en el juicio que le hace la historia y la literatura. Su acción heroica se transforma en su mejor caricatura. El tiempo le condena y la narrativa se encarga de infringirle el castigo. Sobre el papel jugado en el Descubrimiento gravita su egoísmo y su olvido de la comunidad, ya sea española o indígena.

Conforme avanza el tiempo en el siglo $\mathrm{XX}$, la mirada americana sobre Colón y el Descubrimiento resemantizan la figura del descubridor. Caprichoso, vano, violento, víctima de un temperamento que se puede calificar de melancólico, la efigie de Cristóbal Colón se pervierte y muestra su otra máscara, la del germen del horror. A las obras de Alejo Carpentier y Roa Bastos, que con tanto acierto analizara Rosa Pellicer ${ }^{50}$, se suman otras cuyo tema es la conquista como Réquiem en Castilla del Oro, de Julio Valle Castillo. El hecho de reincidir la nueva novela en la figura de Colón nos lleva a considerar el descubrimiento como una de las calas que troquela el pensamiento de la identidad.

Como dirá Darío, la antorcha, el fuego de los dioses, está en manos de los pueblos americanos, «Los modernos Ícaros», descubridores en potencia de un continente desconocido, rico en futuro, la nueva Atlántida, el paraíso. Campo para la Utopía.

Y si el luchador ha de triunfar, triunfará, pues la fatalidad del bien es igual a la fatalidad del mal, y en donde el acorazado que sabe a dónde se dirige, se hunde, la Carabela de Colón, pasa, guiada por el destino hacia en donde ha de aparecer la deseada América. 